\title{
Novel Cathode Material for Rechargeable Lithium-Sulfur Batteries
}

\author{
Oliver Gronwald, Arnd Garsuch, and Alexander Panchenko
}

\begin{abstract}
This article describes the synthesis and characterization of a novel crosslinked polymer with tricyanuric acid core bearing tetrasulfide bridges as a novel redox polymerization electrode material for rechargeable lithiumsulfur batteries. The new material was synthesized by reaction of stoichiometric sulfur monochloride amounts with trithiocyanuric acid and the structure of the redox polymer proven by the means of elementary analysis, infrared spectroscopy and Raman spectroscopy. Electrochemical evaluation of the polymer as electroactive cathode component showed cycling stability up to 140 cycles after initial capacity of $650 \mathrm{mAhg}^{-1}$ with $73 \%$ utilization of the theoretical specific capacity $\left(893 \mathrm{mAhg}^{-1}\right)$ regarding the electroactive tetrasulfide moieties. Cell operation with excess amounts of electrolyte did not accelerate the cell degradation, indicating that the reduced sulfur species such as lower polysulfides $\left(\mathrm{Li}_{2} \mathrm{~S}, \mathrm{Li}_{2} \mathrm{~S}_{2}\right)$ and tris lithium salt of trithiocyanuric acid are efficiently immobilized on the cathode side.
\end{abstract}

Keywords: Cathode · Depolymerization · Lithium-sulfur battery · Redox polymer · Tetrasulfide crosslink · Trithiocyanuric acid core

\section{Introduction}

Current lithium-ion batteries (LIB) based on intercalation materials can potentially provide only energy densities up to $200 \mathrm{Wh} \mathrm{kg}^{-1}$, which restricts their use as power sources for long driving range $(>300$ $\mathrm{km}$ ) pure electric vehicles (PEVs) and plugin electric vehicles (PHEV). Rechargeable lithium-sulfur $(\mathrm{Li} / \mathrm{S})$ batteries are believed to be a very promising alternative. The system offers much higher energy density and is relatively inexpensive due to a large annual surplus of elemental sulfur generated as side product from hydrodesulfurization petroleum refining processes, which is available worldwide..$^{[1]}$ Theoretical energy density values can approach $2500 \mathrm{Wh} \mathrm{kg}^{-1}$ with practical values of $500-600 \mathrm{Wh} \mathrm{kg}^{-1}$ assuming the complete electrochemical conversion of sulfur $\left(\mathrm{S}_{8}\right)$ to lithium sulfide $\left(\mathrm{Li}_{2} \mathrm{~S}\right)$. Therefore, lithium-sulfur batteries have been investigated for mobile and por-

${ }^{\star}$ Correspondence: Dr. O. Gronwald

BASF SE

GMV/P - B1

67056 Ludwigshafen

Germany

Tel.: +496216043285

E-mail: oliver.gronwald@basf.com table applications, especially high-energy applications. ${ }^{[2]}$

Fig. 1 outlines the operation principle of the lithium-sulfur battery system. Lithium as anode material offers several advantages over other materials due to its negative electrochemical potential and its wide electrochemical window in combination with other materials, its light weight and thus highest gravimetric energy density among all metallic anode materials. The active cathode material in lithium-sulfur batteries consists of sulfur. Concentration of sulfur in the cathode can vary between 30 to $80 \mathrm{wt} \%$. Due to the electronic insulation properties of sulfur the presence of further additives is required. As conduc- tive additives carbon (20-60 wt $\%$ ) and additional binders (1-10 wt\%) to ensure the mechanical integrity of the cathode layer are employed.

Currently, quick capacity fading and low sulfur utilization are the main obstacles for using $\mathrm{Li} / \mathrm{S}$ as rechargeable system. Only about $50 \%$ or $\sim 800 \mathrm{mAhg}^{-1}$ of $1672 \mathrm{mAhg}^{-1}$ as theoretical capacity can be used. The reason is the "polysulfide shuttle' mechanism (Fig. 2). Elemental sulfur molecules accept electrons during the first discharge process and are gradually converted from higher order to lower order polysulfides. Lower polysulfides with fewer than three sulfur atoms $\left(\mathrm{Li}_{2} \mathrm{~S}_{3}\right)$ are insoluble in the electrolyte so that the

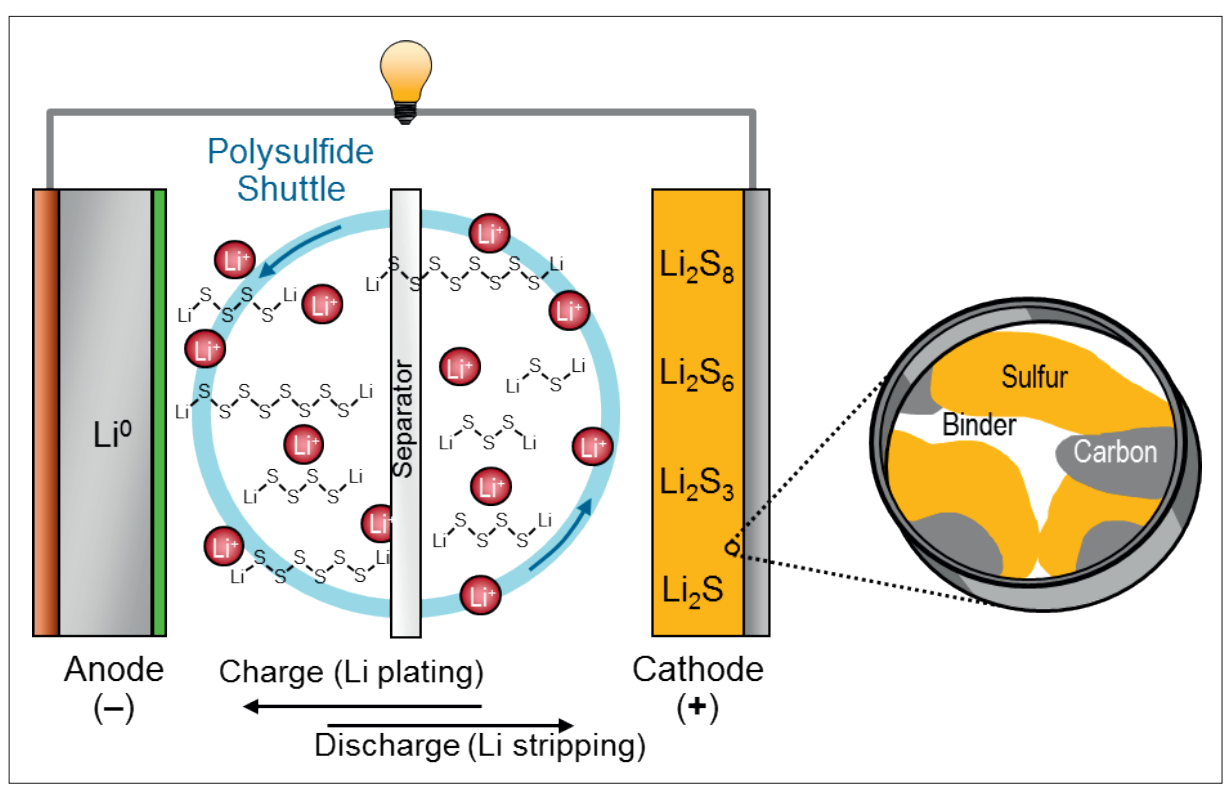

Fig. 1. Operation principle of a lithium-sulfur battery. 
following reduction step to the insoluble and electronically non-conductive $\mathrm{Li}_{2} \mathrm{~S}_{2}$ is hampered. Thus, low discharge efficiencies are observed at rates higher than $\mathrm{C} / 10$ (value of the current used to charge and discharge cells and batteries as a multiple of the capacity). ${ }^{[3]}$ In addition, the polysulfides are not transformed to elemental sulfur during the charging cycles. Instead of being oxidized to sulfur in the final step, the higher order polysulfides constantly diffuse to the anode where they are gradually reduced by the elemental lithium to lower polysulfides in a parasitic reaction. The soluble lower polysulfides then diffuse back to the cathode thus establishing the 'polysulfide shuttle'. Insoluble lower polysulfides precipitate from the electrolyte and accumulate on the anode side. In summary, the mechanism reduces charge efficiency and causes anode and cathode corrosion. As a result, Li/S batteries suffer from capacity fading and a lack of cycle lifetime. Typical state of the art Li/S battery systems can reach lifetimes of $50-80$ cycles.

In order to restrict the polysulfide shuttle and improve the cycling stability there are various solution strategies to overcome the obstacles of the Li/S system. Mostly these approaches focus on novel cathode architectures with new materials. Wang et al. suggested the employment of the dehydrogenation product of sulfur mixtures with polyacrylonitrile as nanodispersed cathode composite ${ }^{4]}$, which can be also used with carbonate-based electrolytes. ${ }^{[5]}$ Also, sulfur-polypyrrole composites ${ }^{[6]}$ have been investigated and strategies to encapsulate sulfur suggested. [7] Highly ordered mesoporous carbon ${ }^{[8 \mathrm{a}, \mathrm{b}]}$ and disordered carbon nanotubes ${ }^{[8 c]}$ impregnated with sulfur, as well as graphene-wrapped sulfur particles ${ }^{[8 \mathrm{~d}]}$ have been considered as cathode materials. Concepts using modified Nafion as barrier have also been discussed. [9] Electrode additives such as lithium nitrate $\left(\mathrm{LiNO}_{3}\right){ }^{[10 a]}$ or phosphorous pentasulfide $\left(\mathrm{P}_{2} \mathrm{~S}_{5}\right)^{310 \mathrm{~b}]}$ form a passivation layer on the lithium anode and block the chemical reactions of polysulfides thus improving coulomb and cycling efficiency in lithium sulfur batteries.

Polymeric disulfides for redox polymerization electrodes were investigated as interesting alternative to elemental sulfur as electroactive species. ${ }^{[11]}$ The reversible electropolymerization/depolymerization of the simple thiolate/disulfide complex avoids the formation of soluble polysulfides. However, compared to elemental sulfur these compounds exhibit limited specific capacities from $350 \sim 600$ $\mathrm{mAhg}^{-1} \cdot{ }^{[12]}$

This study deals with the synthesis and evaluation of a novel, crosslinked polymer including higher polysulfide functional-

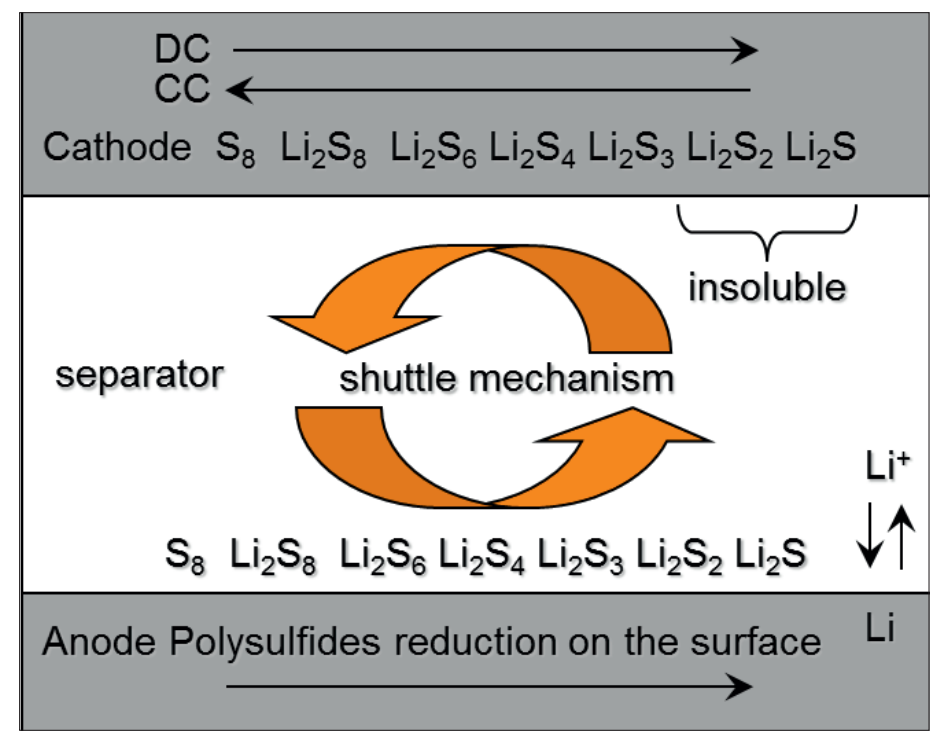

Fig. 2. Polysulfide shuttle in lithiumsulfur batteries. Reproduced according to ref. [3].

ities such as tetrasulfides $(\mathrm{x}=8)$ to improve the specific capacity. In addition, the use of tetrasulfide bridged polymers is expected to result in direct formation of lower, insoluble polysulfides $\left(\mathrm{k}=1,2: \mathrm{Li}_{2} \mathrm{~S}_{2}, \mathrm{Li}_{2} \mathrm{~S}\right)$ along with the thiolate moieties $(\mathrm{x}=2,4$ and 6) upon reduction and depolymerization, thus suppressing the generation of higher polysulfides responsible for the polysulfide shuttle (Scheme 1). Improved cycling stability should be achieved.

\section{Materials and Methods}

\subsection{Preparation of poly (tri-dithiocyanuric acid) (1)}

$5 \mathrm{~g}(28.2 \mathrm{mmol}, \mathrm{M}=177.27 \mathrm{~g} / \mathrm{mol})$ trithiocyanuric acid (Alfa Aesar) was dissolved in $200 \mathrm{ml}$ of anhydrous tetrahydrofuran and $5.7 \mathrm{~g}$ (42.3 mmol, $\mathrm{M}=135.04$ $\mathrm{g} / \mathrm{mol}$ ) sulfur monochloride (Aldrich) was added in small portions. The released hydrochloric acid was removed by a constant nitrogen stream. After the addition was completed, the precipitate was filtered off, washed with tetrahydrofuran and dried overnight in vacuum at $50{ }^{\circ} \mathrm{C}$. Yield: $7.6 \mathrm{~g}$ (99\%) yellowish solid.

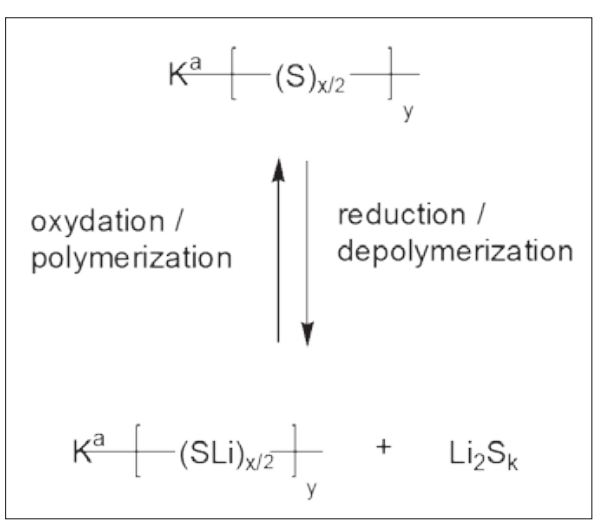

Scheme 1. Redox polymerization/depolymerization in polysulfide-bridged polymers.
Elemental analysis $\left(\mathrm{C}_{3} \mathrm{~N}_{3} \mathrm{~S}_{6}\right)$ : Carbon $14.2 \mathrm{wt} \%$ (calc. $13.33 \mathrm{wt} \%$ ); sulfur : 70.0 wt $\%$ (calc. $71.13 \mathrm{wt} \%$ ); nitrogen: $15.1 \mathrm{wt} \%$ (calc. $15.44 \mathrm{wt} \%$ ); hydrogen: $<0.5 \mathrm{wt} \%$.

IR $(\mathrm{KBr}) v=3449(\mathrm{~m}), 1473(\mathrm{~s}), 1234$ (s), $826(\mathrm{~m}), 783(\mathrm{w}), 535(\mathrm{w}), 495(\mathrm{w})$, $451(\mathrm{w}) \mathrm{cm}^{-1}$.

$\operatorname{Raman}(532 \mathrm{~nm}) \mathrm{v}=186(\mathrm{w}), 221(\mathrm{~m})$, $291(\mathrm{w}), 352$ (w), 443 (s), 468 (s), 500 (m), $535(\mathrm{~m}), 821(\mathrm{w}), 965$ (s), $1250(\mathrm{w})$, $1462(\mathrm{~m}), 1484(\mathrm{~m}) \mathrm{cm}^{-1}$.

\subsection{Preparation of Cathodes}

$7 \mathrm{~g}$ polymer (1) was homogenized with $0.7 \mathrm{~g}$ Printex XE2 (Evonik) and $0.7 \mathrm{~g}$ wolfram carbide in a mortar to yield $8.3 \mathrm{~g}$ polymer composite. To prepare the ink, polyvinyl alcohol (0.5 g) was dissolved in $80 \mathrm{~g}$ mixture of water/isopropanol and 1.62 g Super P (Timcal AG, 6743 Bodio, Switzerland) and $7.69 \mathrm{~g}$ polymer composite added. The mixture was stirred and subsequently dispersed in a pebble mill (Pulverisette, Fa. Fritsch) for $30 \mathrm{~min}$ at $300 \mathrm{rpm}$ to yield homogeneous ink with pasty texture. To coat the cathode ink on aluminium foil (thickness $20 \mu \mathrm{m}$ ) at $60^{\circ} \mathrm{C}$, an air brush system with nitrogen as carrier gas was used. Cathodes with loading of $2.5 \mathrm{mg} / \mathrm{cm}^{2}$ were obtained.

To manufacture the reference cathode, polyvinyl alcohol (0.5 g) was dissolved in $80 \mathrm{~g}$ mixture of water/isopropanol and 1.25 g Super P (Timcal AG, 6743 Bodio, Switzerland), $0.07 \mathrm{~g}$ graphite KS6 (Timcal AG, 6743 Bodio, Switzerland) and $0.03 \mathrm{~g}$ sulfur were added. The mixture was stirred and subsequently dispersed in a pebble mill (Pulverisette, Fa. Fritsch) for $30 \mathrm{~min}$ at $300 \mathrm{rpm}$ to yield homogeneous ink with pasty texture. To coat the cathode ink on aluminium foil (thickness $20 \mu \mathrm{m}$ ) at 60 ${ }^{\circ} \mathrm{C}$, an air brush system with nitrogen as carrier gas was used. Reference cathodes with loading of $2.5 \mathrm{mg} / \mathrm{cm}^{2}$ were obtained. 


\subsection{Electrochemical Characterization}

Electrochemical properties of the cathode materials were evaluated in coin cells. The active surface area was $3.14 \mathrm{~cm}^{2}$. Lithium foil (thickness $50 \mu \mathrm{m}$ ) was used as anode.

The electrochemical investigations were done within a potential range of 1.7$2.5 \mathrm{~V}$ in a pouch cell as shown in Fig. 1 . Charging of the cell was performed with $0.125 \mathrm{C}$-rate, discharging with $0.2 \mathrm{C}$-rate by using a MACCOR cycling equipment at room temperature. Employed electrolyte consisted of 1,2-dimethoxyethane/dioxolane $(1: 1, \mathrm{vol} / \mathrm{vol})$ with $1 \mathrm{~mol} / \mathrm{l}$ lithium bis(trifluromethansulfonimide) as conducting salt. Celgard 2340 with a thickness of $38 \mu \mathrm{m}$ was used as separator. The capacity was standardized on the specific capacity of the active cathode materials employed in the electrode. Calculated on the basis of the sulfur employed in the cathode with $100 \%$ utilization the maximum capacity of $1672 \mathrm{mAg}^{-1}$ can be achieved. For poly(tri-dithiocyanuric acid) (1) the maximum capacity of $893 \mathrm{mAg}^{-1}$ can be reached. In Figs 4 and 6 the discharge capacities are depicted as relative capacities based on the individual maximum capacity of each active material.

\section{Results and Discussion}

Redox polymerization electrode materials based on carbon-sulfur bonds, $-\mathrm{C}-\mathrm{S}-$ $\mathrm{S}-\mathrm{C}-$, can be prepared either by oxidation of mercaptans or lithium thiolate salts by iodine. ${ }^{[11 \mathrm{a}]}$ For polymers based on nitrogen-sulfur bonds, $-\mathrm{N}-\mathrm{S}-\mathrm{S}-\mathrm{N}-$, conversion of the primary or secondary amines with sulfur monochloride $\left(\mathrm{S}_{2} \mathrm{Cl}_{2}\right)$ can be employed. [12] Since arylsulfurchlorides can be converted with arylsulfides in a clean reaction to mixed aryldisulfides and hydrochloric acid,[13] we approached the synthesis of poly (tri-dithiocyanuric acid) (1) using sulfur monochloride as reagent. Trithiocyanuric acid was dissolved in anhydrous tetrahydrofuran and treated with stoichiometric amount of sulfur monochloride. The released hydrochloric acid was removed under a steady stream of nitrogen (Scheme 2).

Upon addition of sulfur monochloride crosslinked poly(tri-dithiocyanuric acid) (1) precipitated and was filtered off after reaction completion. To remove impurities the product was washed several times with tetrahydrofuran, finally dried overnight under vacuum and obtained in quantitative yield. Elementary analysis indicates the successful transformation. Compared to the theoretical values of the starting material trithiocyanuric acid (carbon: $20.33 \%$, nitrogen: $23.71 \%$, hydrogen: $1.17 \%$, sul-

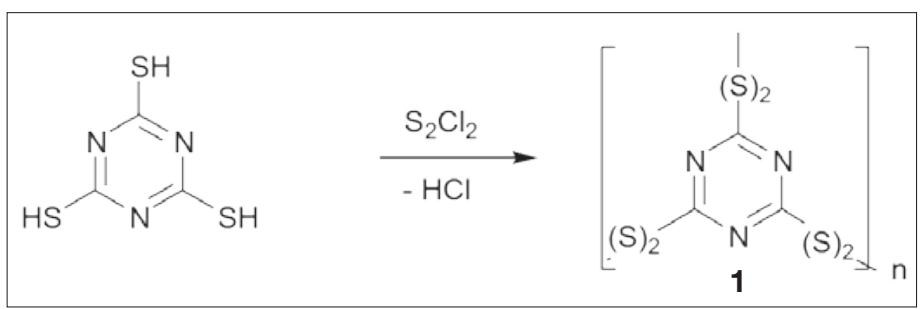

Scheme 2. Synthesis of tetrasulfidebridged polymer based on trithiocyanuric acid.

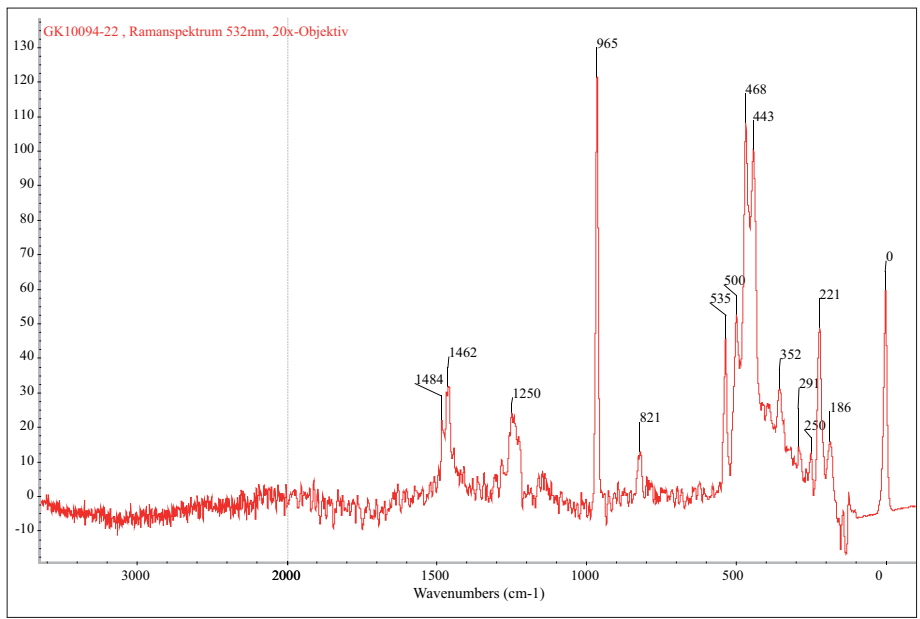

Fig. 3. Raman spectroscopy (532 nm) of poly(tri-dithiocyanuric acid) (1).

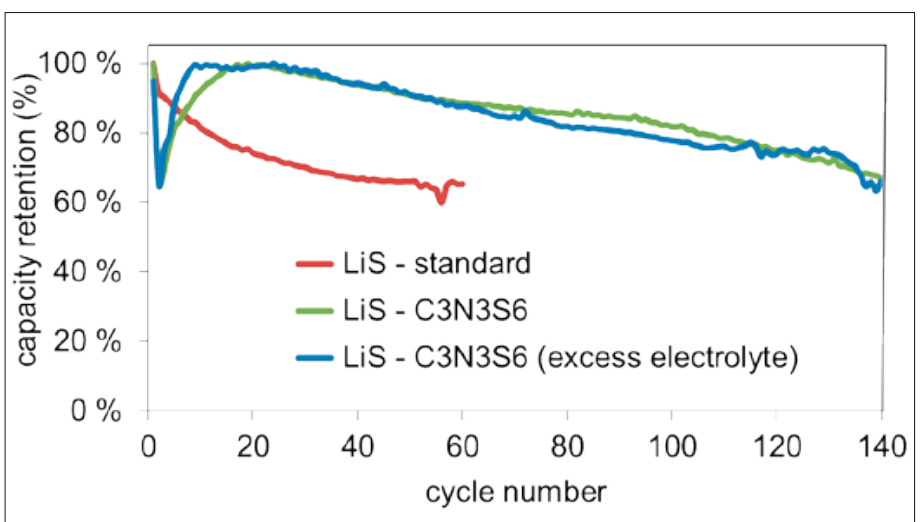

Fig. 4. Discharge capacities of lithium sulfur cells equipped with cathode containing polymer $\mathbf{1}$ as electroactive species including various electrolyte amounts (green: standard, red: 1.5 times electrolyte amount) and lithium-sulfur standard cathode (red) at 0.2 C-rate.

fur: $54.25 \%$ ) experimental values of the crosslinked product $\mathbf{1}$ show significantly higher proportion of sulfur: $70.0 \%$ and reduced contents for carbon: $14.2 \%$, nitrogen: $15.1 \%$ and hydrogen: $<0.5 \%$. In addition, the acceptable agreement with the theoretical values for poly (tri-dithiocyanuric acid) (carbon: $13.33 \%$, nitrogen: $15.54 \%$, sulfur: $71.13 \%$ ) indicate the successful incorporation of disulfide moieties. The deviations and the presence of hydrogen $(<0.5 \%)$ can be assigned to some remaining mercapto groups and traces of solvent trapped in the product by the immediately starting precipitation process during synthesis.

Solid-state infrared analysis in potassium bromide supports these findings. Compared to trithiocyanuric acid as starting material the weak but characteristic valence vibrations for thiols from 2550-2600 $\mathrm{cm}^{-1}$ and $600-800 \mathrm{~cm}^{-1}[14]$ are missing. In addition, characteristic stretching vibrations for $\mathrm{R}-\mathrm{S}_{4}-\mathrm{R}$ groups in the fingerprint region of $470-489 \mathrm{~cm}^{-1[15]}$ appear at 495 $\mathrm{cm}^{-1}$. More detailed information was obtained by Raman spectroscopy at $532 \mathrm{~nm}$. Sulfur-sulfur stretching vibrations are clearly visible at 468 and $500 \mathrm{~cm}^{-1}$ (Fig. 3) compared to the trithiocyanuric acid which shows mayor signals at 221, 447, 1123 and $1269 \mathrm{~cm}^{-1}$.

Thermogravimetric analysis under air indicates thermal stability up to $238^{\circ} \mathrm{C}$ with a weight loss of only $5.9 \mathrm{wt} \%$. Temperature increase to $316.4{ }^{\circ} \mathrm{C}$ triggers a further weight loss of $52.4 \mathrm{wt} \%$. Infrared analysis of the decomposition product proves the presence of carbonsulfuroxide and sulfuroxides. Isocyanates originating from the 1,3,5-triazine core are found together with carbonsulfuroxide and sulfuroxides in the temperature range from 378 to $540{ }^{\circ} \mathrm{C}$ (19.3 wt\% mass loss). In summary, results of elemental analysis, infrared and Raman spectroscopy and thermogravimetric analysis coupled with infrared spectroscopy results are in good agreement with the postulated presence of tetrasulfide bridges in poly(tri-disulfidecyanuric acid). 
The theoretical capacity for a repeating unit $\mathrm{C}_{3} \mathrm{~N}_{3} \mathrm{~S}_{6}$ in compound $\mathbf{1}$ with a molecular weight of $270.2 \mathrm{~g} / \mathrm{mol}$ was estimated to $893 \mathrm{mAhg}^{-1}$, assuming the complete reduction of all $\mathrm{R}-\mathrm{S}-\mathrm{S}-\mathrm{S}-\mathrm{S}-\mathrm{R}$ moieties with nine electrons to $\mathrm{R}-\mathrm{SLi}$ and lithium disulfide $\left(\mathrm{Li}_{2} \mathrm{~S}\right)$. Compared to its disulfide-bridged analogue of trithiocyanuric acid with $460 \mathrm{mAhg}^{-1}$ specific capacity, ${ }^{[12]}$ polymer 1 offers almost double specific capacity and nearly half the specific capacity of sulfur $\left(1672 \mathrm{mAhg}^{-1}\right)$. In addition, every step of the reduction process involves direct formation of electrolyte insoluble lower polysulfides $\left(\mathrm{Li}_{2} \mathrm{~S}_{2}\right.$ and $\left.\mathrm{Li}_{2} \mathrm{~S}\right)$, the tris lithium salt of trithiocyanuric acid and covalently bound lithium thiolate moieties thus restricting the formation of the polysulfide shuttle.

Fig. 4 displays the discharge capacities of Li/S-cells equipped with cathode employing $\mathbf{1}$ as active material and two different electrolyte amounts. In addition, the discharge capacity of a standard sulfur cathode is given for comparison. Using the standard amount of electrolyte the initial discharging capacity improves within the first 20 cycles up to $650 \mathrm{mAhg}^{-1}$ which accounts for roughly $73 \%$ electrochemical utilization of polymer 1 . After 140 cycles capacity retention of $65 \%$ is observed. Offering higher amounts of electrolyte (1.5 times) triggers rapid equilibration to the maximal initial discharging capacity of $580 \mathrm{mAhg}^{-1}$ within 10 cycles. Obviously the presence of excess electrolyte reduces the break-in time of the cathode. On the other hand, the presence of higher electrolyte amounts usually promotes polysulfide leaching from sulfur based cathode and therefore effectively reduces their durability. For the cathode with polymer $\mathbf{1}$ as active material, however, the presence of excess electrolyte does not accelerate the degradation. Compared to electrochemical cells with standard amount electrolyte similar capacity fading to $65 \%$ retention after 140 cycles is found. As consequence, the reduction products of polymer $\mathbf{1}$ must be less soluble in the electrolyte compared to elemental sulfur in standard cathodes. For the standard system comprising electroactive sulfur $65 \%$ capacity retention is already found after 40 charge and discharge cycles. As further aspect, the electrochemical utilization rate of $73 \%$ for polymer 1 indicates that not all tetrasulfide moieties are completely accessible to the electro depolymerization process and reduced to $\mathrm{R}-\mathrm{SLi}$ and $\mathrm{Li}_{2} \mathrm{~S}$. But comparing the relative electrochemical utilization polymer $\mathbf{1}$ of $73 \%$ to elemental sulfur with $66 \%$ utilization the efficiency of the new polymer material can be considered slightly superior to elemental sulfur. In summary, polymer 1 provides as active cathode material compared to elemental sulfur improved

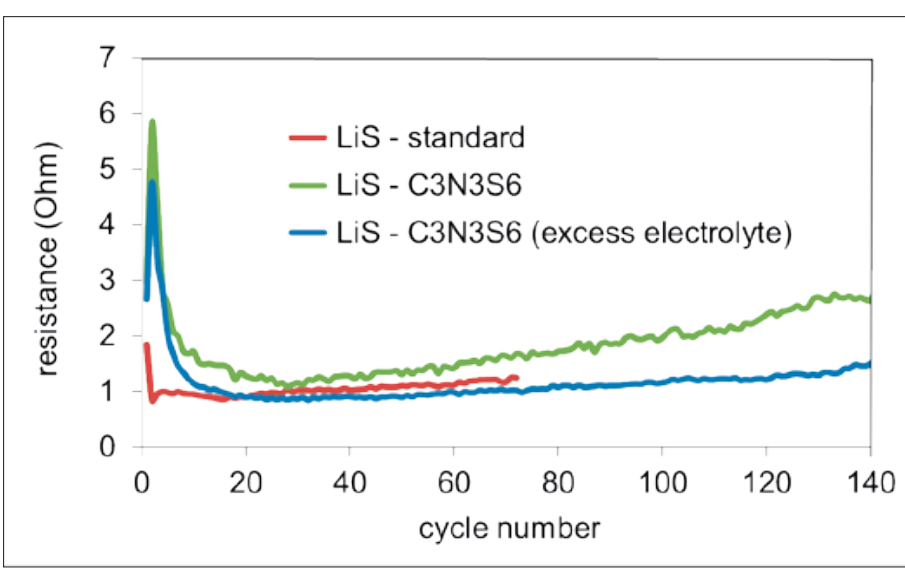

Fig. 5. Impedance (resistance) of lithiumsulfur cells equipped with cathode containing polymer $\mathbf{1}$ as electroactive species including various electrolyte amounts (green: standard, red: 1.5 times electrolyte amount) and lithium-sulfur standard cathode (red) at 0.2 C-rate.

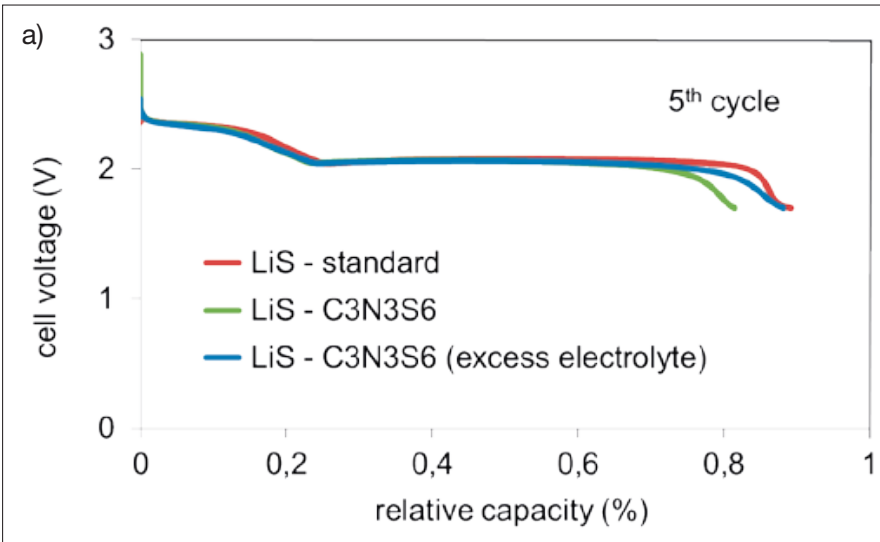

Fig. 6. Discharge profiles of lithium-sulfur cells equipped with cathode containing polymer 1 as electroactive species including various electrolyte amounts (green: standard, red: 1.5 times electrolyte amount) and lithium-sulfur standard cathode (red) at 0.2 C-rate a) cycle 5; b) cycle 50; c) cycle 100 .
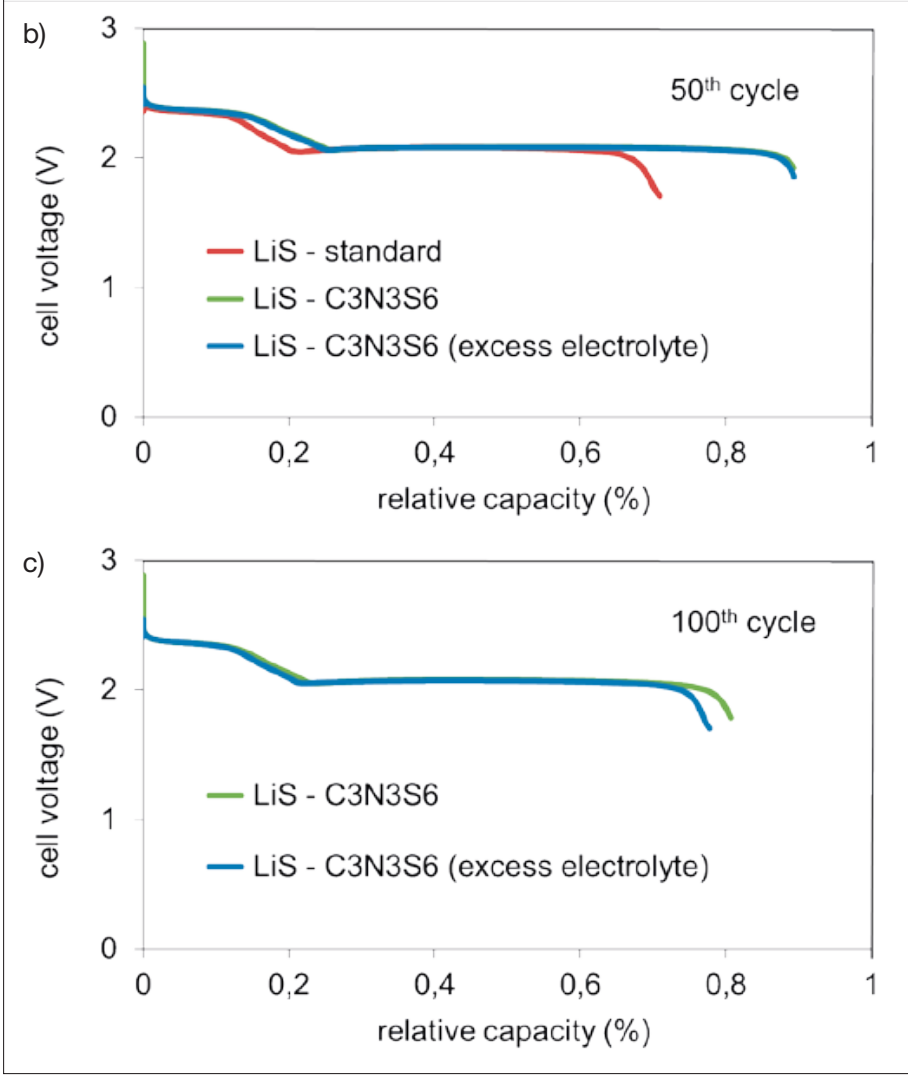

cycling stability and improved utilization efficiency.

Analysis of the cell resistance (Fig. 5) also demonstrates the impact of electrolyte amount. With excess amounts of electrolytes a resistance of $1 \Omega$ is found after 20 cycles break-in time for cathode employing polymer $\mathbf{1}$ as active material. In contrast, usage of lower electrolyte amounts results in resistance of $1.5 \Omega$ after 20 cycles. It can be reasoned that the presence of excess electrolyte allows better penetration of the cathode and separator, thus improving the accessibility of electroactive species and 
reducing the resistance. Upon operation, cell resistance increases gradually for all three cells at similar rates. Again, this suggests the stability of the novel tetrasulfide based cathode material $\mathbf{1}$, since the depolymerization process does not allow the formation of soluble polysulfides to trigger the polysulfide shuttle. Nevertheless, even this novel cathode material shows capacity fading, which might be ascribed to the assumed formation of higher polysulfides during the oxidation and polymerization process since the exclusive reformation of tetrasulfide bridges is not certain. Once formed, the higher soluble polysulfides can trigger the polysulfide shuttle.

Analysis of the discharge profiles under operation for cathodes employing sulfur and material $\mathbf{1}$ as active materials (Fig. 6 ) after 5 cycles does not reveal any major differences.

In general, the discharge profile reflects the three stage process of sulfur cell discharge in organic electrolytes:[2a] from $2.4 \mathrm{~V}$ to the first plateau at $2.1 \mathrm{~V}$ sulfur is reduced to soluble polysulfides $\left(\mathrm{Li}_{2} \mathrm{~S}_{8}\right.$ to $\mathrm{Li}_{2} \mathrm{~S}_{3}$ ). The plateau region at $2.1 \mathrm{~V}$ then reflects reduction to insoluble $\mathrm{Li}_{2} \mathrm{~S}_{2}$ whereas the final discharge region from 2.1 to $1.7 \mathrm{~V}$ represents the inter conversion from $\mathrm{Li}_{2} \mathrm{~S}_{2}$ to $\mathrm{Li}_{2} \mathrm{~S}$ which is most difficult due to the sluggishness of solid-state diffusion in the bulk. After 50 and 100 cycles, for the cathode employing polymer $\mathbf{1}$ as active material, the plateau region and final discharge region from 2.1 to $1.7 \mathrm{~V}\left(\mathrm{Li}_{2} \mathrm{~S}_{2} \rightarrow \mathrm{Li}_{2} \mathrm{~S}\right)$ appears to be more pronounced and similar to discharge profiles of elemental sulfur in the standard cathode.

\section{Conclusion}

Based on trithiocyanuric acid a novel crosslinked polymer bearing tetrasulfide bridges was successfully synthesized as redox polymerization electrode material and evaluated in rechargeable lithium sulfur batteries. The new tetrasulfide-bridged polymer was synthesized by reaction of stoichiometric amounts of sulfur monochloride with trithiocyanuric acid and the structure of the redox polymer proven by means of elementary analysis and infrared spectroscopy. The theoretical specific capacity was calculated as $893 \mathrm{mAhg}^{-1}$ per polymer repeating unit. Upon electrochemical evaluation of the tetrasulfide crosslinked polymer with tricyanuric acid core cycling stability up to 140 cycles with $65 \%$ capacity retention after initial capacity of $650 \mathrm{mAhg}^{-1}$ with utilization of the electroactive tetrasulfide moieties of $73 \%$ was found. The presence of excess electrolyte did not accelerate the cell degradation, thus indicating that reduced sulfur species such as lower polysulfides $\left(\mathrm{Li}_{2} \mathrm{~S}, \mathrm{Li}_{2} \mathrm{~S}_{2}\right)$ and tris lithium salt of trithiocyanuric acid are efficiently immobilized on the cathode side.

In summary, the concept to restrict the polysulfide shuttle in lithium-sulfur batteries employing a tetrasulfide crosslinked redox polymer as cathode novel material which forms lower polysulfide species and tris lithium salt of trithiocyanuric acid with low electrolyte solubility upon redox polymerization was proven to be viable. Compared to disulfide based redoxpolymers with high cycling stability the tetrasulfide bridged polymer with tricyanuric acid core shows higher specific capacity.

\section{Acknowledgement}

The authors acknowledge financial support by German Federal Ministry of Education and Research (BMBF) 'HE-Lion project' and BASF SE for permission to publish this paper.

Received: August 14, 2013

[1] W. J. Chung, J. J. Griebel, E. T. Kim, H. Yoon, A. G. Simmonds, H. J. Ji, P. T. Dirlam, R. S. Glass, J. J. Wie, N. A. Nguyen, B. W. Guralnick, J. Park, A. Somogyi, P. Theato, M. E. Mackay, Y. Sung, K. Char, J. Pyun, Nature Chem. 2013, 5,518 .

[2] a) X. Ji, L. Nazar, J. Mater. Chem. 2010, 20, 9821 , b) P. G. Bruce, S. A. Freunberger, L. J. Hardwick, J.-M. Tarascon, Nature Mater. 2012, 11, 19, c) M.-K. Song, E. J. Cairns, Y. Zhang, Nanoscale 2013, 5, 2186.
[3] J. R. Akridge, Y. V. Mikhaylik, N. White, Solid State Ionics 2004, 175, 243.

[4] a) J. Wang, J. Yang, J. Xie, N. Xu, Adv. Mater. 2002, 14, 963, b) J. Wang, J. Yang, C. Wan, K. Du, J. Xie, N. Xu, Adv. Funct. Mater. 2003, 13, 487, c) X. Yu, J. Xie, Y. Li, H. Huang, C. Lai, K. Wang, J. Power Sources 2005, 146, 335, d) L. Yin, J. Wang, J. Yang, Y. Nuli, J. Mater. Chem. 2011, 21, 6807.

[5] a) J. Fanous, M. Wegner, J. Grimminger, Ä. Andresen, M. Buchmeiser, Chem. Mater. 2011, 23,5024, b) L. Wang, X. He, J. Li, M. Chen, J. Gao, C. Jiang, Electrochim. Acta 2012, 72, 114.

[6] a) J. Wang, J. Chen, K. Konstantinov, L. Zhao, S. H. Ng, G. X. Wang, Z. P. Guo, H. K. Liu, Electrochim. Acta 2006, 51, 4634, b) X. Liang, Z. Wen, Y. Liu, X. Wang, H. Zhang, M. Wu, L. Hiang, Solid State Ionics 2011, 192, 347, c) Y. Zhang, Z. Bakenov, Y. Zhao, A. Konrarov, T. Doan, M. Malik, T. Paron, P. Chen, J. Power Sources 2012, 208, 1, ) X. Liang, Z. Wen, Y. Liu, H. Zhang, J. Jin, M. Wu, X. Wu, J. Power Sources 2012, 206, 409.

[7] a) B. Zhang, X. Qin, G. R. Li, X. P. Gao, Energy Environ. Sci. 2010, 3, 1531, b) G. Zheng, Y. Yang, J. J. Cha, S. S. Hong, Y. Cui, Nano Lett. 2011, 11, 4462, c) N. Jayaprakash, J. Shen, S. S. Moganty, A. Corona, L. A. Archer, Angew. Chem. Int. Ed. 2011, 50, 5904, d) J. Schuster, G. He, B. Mandlmeier, T. Yim, K. T. Lee, T. Bein, L. Nazar, Angew. Chem. Int. Ed. 2012, 51, 3591, e) F. Böttger-Hiller, P. Kempe, G. Cox, M. Rose, S. Kaskel, S. Spange, Angew. Chem. Int. Ed. 2013, 52, 6088.

[8] a) X. Ji, K. Lee, L. Nazar, Nature Mater. 2009, 8 500, b) G. He, X. Ji, L. Nazar, Energy Environ. Sci. 2011, 4, 2878, c) J. Guo, Y. Xu, C. Wang, Nano Lett. 2011, 11, 4288, d) H. Wang, Y. Yang, Y. Liang, J. T. Robinson, Y. Li, A. Jackson, Y. Cui, H. Dai, Nano Lett. 2011, 11, 2644.

[9] a) Z. Jin, K. Xie, X. Hong, Z. Hu, X. Liu, $J$. Power Sources 2012, 218, 163, b) H. Schneider, A. Garsuch, A. Panchenko, O. Gronwald, N. Janssen, P. Novak, J. Power Sources 2012, 205, 420.

[10] a) Y. V. Mikhaylik, US Patent 7354280, 2008, b) Z. Lin, Z. Liu, W. Fu, N. J. Dudney, C. Liang, Adv. Func. Materials 2012, 23, 1064.

[11] a) M. Liu, S. Visco, L. C. Jonghe, J. Electrochem. Soc. 1991, 138, 1891, b) M. Liu, S. Visco, L. C. Jonghe, J. Electrochem. Soc. 1991, 138, 1896.

[12] M. Z. A. Munshi, 'Handbook of Solid State Batteries \& Capacitators', World Scientific Publishing, $1^{\text {st }}$ ed. 1995

[13] H. Lecher, Chem. Berichte 1920, 577.

[14] H. G. O. Becker, 'Organikum: Organisch Chemisches Grundpraktikum', Wiley-VcH, $20^{\text {th }}$ ed. 1998.

[15] B. Trofimov, L. M. Sinegovskaya, N. K. Gusarova, J. Sulfur Chem. 2009, 30, 518. 